Jurnal Konstruksi Hukum | ISSN: XXXX | E-ISSN: XXXX Vol. 1, No. 1, September 2020 Hal. 84-90| Available online at https://www.ejournal.warmadewa.ac.id/index.php/jukonhum DOI: https://doi.org/10.22225/jkh.1.1.2135.84-90

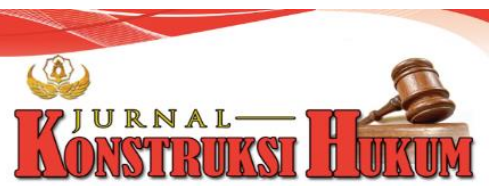

\title{
PELAKSANAAN PERATURAN BUPATI BADUNG NOMOR 38 TAHUN 2018 DALAM PEMBERIAN BANTUAN PERLINDUNGAN SOSIAL BAGI PARA LANJUT USIA DI KABUPATEN BADUNG
}

\author{
Dhiananda Ningrat, I Ketut Sukadana, Desak Gede Dwi Arini \\ Fakultas Hukum Universitas Warmadewa, Denpasar-Bali, Indonesia \\ Dhiananda16@yahoo.com
}

\begin{abstract}
Abstrak
Dalam rangka memanifestasikan kehidupan yang layak serta memenuhi hak untuk kebutuhan dasar masyarakat agar dapat tercapainya kesejahteraan sosial bagi usia lanjut Pemerintah di Mangupura melalui Dinas Sosial menyediakan pelayanan perlindungan sosial kepada para lansia dikabupaten Badung yang dilasanakan secara terarah, terencana dan berkesinambungan. Tujuan penelitian ini yaitu utnuk mengetahui pelaksanaan dalam Pemberian Perlindungan Sosial bagi Lanjut Usia di Kabupaten Badung dan mengetahui faktor penghambat dalam pemberian Bantuan Perlindungan Sosial Lanjut Usia di Kabupaten Badung. Penelitian ini didesain dengan menggunakan penelitian hukum empiris. Ada dua sumber data yang digunakan dalam penelitian primer dan sekunder melalui penelitian dilapangan dan bahan sekunder tulisan para ahli dan hasil para ilmuwan kemudian diolah dan dianalisis secara deskriptif guna mendapatkan suatu kesimpulan. Hasil penelitian menunjukan bahwa Pelaksanaan Bantuan lanjut usia bertujuan untuk memberikan bantuan sosial bagi Lansia yang ada di Kabupaten Badung bahwa faktor hambatan yang dihadapi oleh dinas sosial dalam penyaluran bantuan sosial dikarenakan tidak sinkronisasinya data yang ada di Desa/Kelurahan dengan Data yang ada di Dinas Sosial Kabupaten Badung. Saran yang diberikan penulis diharapkan ada sinkronisasi antara pendataan yang dilakukan oleh aparat Desa/ Kelurahan terkait jumlah lansia yang ada dimasing-masing wilayah sehingga bantuan tunjangan sosial dapat dibagikan secara merata dan tepat sasaran sehingga bantuan yang disalurkan menjadi tepat guna.
\end{abstract}

Kata Kunci: Dinas Sosial, Bantuan Kesejahteraan Sosial, Lansia

\begin{abstract}
In order to manifest a decent life and fulfill the rights to basic needs of the community in order to achieve social welfare for the elderly, the Government in Mangupura through the Social Service provides social protection services to the elderly in Badung Regency which are carried out in a directed, planned and sustainable manner. The purpose of this study is to determine the implementation of the provision of social protection for the elderly in Badung Regency and to find out the inhibiting factors in providing Advanced Social Protection Assistance. Age in Badung Regency. This research was designed using empirical legal research. There are two sources of data used in primary and secondary research through field research and secondary materials written by experts and scientists' results are then processed and analyzed descriptively in order to obtain a conclusion. The results showed that the implementation of elderly assistance aims to provide social assistance for the elderly in Badung Regency that the obstacle factor faced by the social services in distributing social assistance is due to the unsynchronization of the data in the Village / Kelurahan with the data in the Social Service, Badung Regency. The suggestion given by the author is that it is hoped that there will be synchronization between the data collection carried out by the village / kelurahan apparatus regarding the number of elderly people in each area so that social allowance assistance can be distributed evenly and on target so that the assistance distributed becomes efficient.
\end{abstract}

Keywords: Social Service, Social Welfare Assistance, Elderly

\section{PENDAHULUAN}

Peradaban Nasional Indonesia yang secara resmi dimulai sejak Proklamasi Kemerdekaan 17 Agustus 1945 pada kenyataannya memiliki tujuan untuk membentuk manusia dan masyarakat pribumi ini sepenuhnya. Terlaksananya fungsi dan tanggungjawab yang memuat esensi pembangunan insan atau masyarakat seutuhnya hanya bisa dicapai melalui penciptaan rakyat yang merata dan sejahtera baru dapat dilaksanakan secara sungguh-sungguh mulai pemerintahan orde baru hingga dewasa ini (Subakti, 2001:9). Lansia merupakan seseorang yang telah memasuki usia 60 tahun dan dilihat secara 
fisik maupun mental cenderung mengalami penurunan. Dengan perubahan fisik dan tingkah laku yang terjadi pada semua orang saat mereka mencapai usia lanjut. Berdasarkan karakteristik lingkungan sosial yang menganggap bahwa orang telah tua saat ia menunjukkan ciri seperti rambut beruban rontok kulit keriput dan hilangnya gigi (Azizah, 2011:2).

Untuk mewujudkan taraf hidup yang lebih baik dan bermanfaat serta mendapatkan hak dari kebutuhan dasar masyarakyat untuk tercapainya kesejahteraan bagi lanjut usia di Pemerintahan Kabupaten Badung melalui Dinas Sosial menyalurkan bantuan yaitu perlindungan sosial kepada lanjut usia dikabupaten Badung yang dilakukan secara teragenda matang dan berkelanjutan. Penyaluran Santunan Sosial kepada lansia dengan diterbitkannya tatanan Peraturan Bupati Badung No 38 Tahun 2018 tentang bantuan perlindungan sosial lanjut.

Santunan bagi warga lanjut usia Kabupaten Badung di launching pada puncak HUT Mangupura ke 9 yang jatuh pada tanggal 16 November 2018. Dinas Sosial Kabupaten Badung telah selesai melaksanakan verifikasi. Lansia yang berhak menerima satunan berjumlah 13.104 perorang yang nominalnya sebesar Rp. 1.000.000, - (satu juta rupiah). Dalam melakukan verifikasi kelapangan Dinas Sosial bekerjasama dengan Perbekel/ Lurah masing-masing desa yang ada di Kabupaten Badung. Lansia yang menerima santunan di Kabupaten Badung berdasarkan Surat Keputusan Pencairan Dana Bantuan Sosial Lansia yang ditandatangani oleh Bupati Badung. Salah satu tolak ukur penerima santunan adalah Para lansia yang potensial paling rendah umur 72 tahun, sedangkan lansia yang berumur 60 tahun ke atas yaitu kondisi cuma berbaring tak berdaya (bedridden), bukan lanjut usia yang sedang menerima pensiunan/ sokongan pemerintah maupun badan sosial, dan bukan lanjut usia yang menjadi binaan dan tanggungjawab Panti Wredha.

Beberapa penelitian terkait lanjut usia telah dikaji oleh peneliti sebelumnya seperti Cirella, Bąk, Kozlak, Pawłowska, \& Borkowski (2019); Knapik (2020); Liu, Qu, Meng, \& Wang (2020); Pak (2020); Supromin \& Choonhakhlai, (2019) mengatakan bahwa faktor-faktor yang mempengaruhi keberhasilan pemerintah kota dalam memberikan pelayanan publik kepada lanjut usia dibagi menjadi dua bagian: 1) faktor internal organisasi seperti kepemimpinan pembuat keputusan kota, otonomi dalam pengambilan kebijakan, informasi yang benar dan terkini, personil yang berkomitmen, dan anggaran ; dan 2) faktor eksternal organisasi seperti kebijakan nasional, rencana dan undang-undang untuk lanjut usia, instansi pemerintah yang bertanggung jawab untuk lanjut usia, dan kemitraan dan jaringan pemangku kepentingan. Berdasarkan latar belakang masalah di atas, maka penelitian baru ini bertujuan untuk mengetahui pelaksanaan dalam pemberian bantuan perlindungan sosial bagi lansia di Kabupaten Badung dan mengetahui faktor penghambat dalam pemberian bantuan perlindungan sosial lansia di Kabupaten Badung.

\section{METODE PENELITIAN}

Metode yang digunakan dalam penelitian ini adalah pendekatan penelitian hukum Empiris. Penggunaan pendekataan ini berkaitan dengan pemberlakuan atau implementasi kepastian hukum kepada setiap peristiwa tertentu yang timbul dimasyarakat (Muhamad, 2004:134). Ada dua bentuk sumber data yang digunakan yaitu data primer dan data sekunder. Lokasi yang dipilih untuk mendapatkan data primer adalah di Kantor Dinas Sosial Kabupaten Badung yang diperoleh secara langsung melalui pendataan lapangan yang berasal dari informan yaitu lansia yang menerima Bantuan Sosial di Kabupaten Badung dan data sekunder yaitu data yang diperoleh dari penelitian kepustakaan yang terdiri dari Sumber Hukum Primer berupa Undang - Undang Dasar Negara Republik Indonesia tahun 1945, Undang-Undang Nomor 13 Tahun 1998 tentang Kesejahteraan Lanjut Usia, Undang Undang Nomor 23 Tahun 2014 tentan Perda, Peraturan Bupati Badung Nomor 38 Tahun 2018 tentang Bantuan Perlindungan Sosial Lanjut Usia. Teknik pengumpulan data dalam penelitian ini menggunakan teknik observasi dan wawancara langsung dengan informan di Kantor Dinas Sosial Kabupaten Badung. Kemudian, data yang dikumpulkan dianalisis dengan menggunakan teknik analisis kualitatif. Setelah itu, data disajikan dalam bentuk table dan kemudian diinterpretasikan melalui deskriptif teks.

\section{HASIL DAN PEMBAHASAN}

Kelompok penduduk lanjut usia kerap diartikan seperti seseorang yang tidak mampu menghasilkan atau tidak aktif lagi. Pemikiran inipun merugikan bagi para lansia, lantaran disisi lain ada Lansia masih mampu produktif. Salah satu pemasalahan yang muncul akibat tingginya angka lansia adalah 
tingginya penduduk yang tidak bisa menghasilkan lagi. Para lanjut usia sering di cap sebagai pikulan keluarga. Di negara- negara yang sudah maju perhatian terhadap lansia adalah menjadi prioritas pemerintah dimana pemerintah memberikan santunan yang relatif cukup kepada para lansia. Sebaliknya di negara-negara berkembang jaminan sosial penduduk lansia belumlah begitu diperhitungkan.

Menurut WHO Lansia adalah seseorang yang telah memasuki umur 60 tahun keatas. Lansia merupakan kelompok umur yang telah memasuki tahap akhir dari fase kehidupanya. Kelompok yang dikatagorikan Lansia ini akan terjadi suatu proses yang disebut Aging Process atau Proses Penuaan. Proses Penuaan adalah siklus kehidupan dengan tahapan-tahapan menurunnya berbagai fungsi organ tubuh yang ditandai dengan semakin rentannya tubuh terhadap berbagai penyakit yang dapat menyebabkan kematian. Batasan umur usia lanjut menurut WHO adalah:

a. Usia Pertengahan (middle Age) antara usia 45 sampai 59 tahun;

b. Lanjut Usia (elderly) antara 60 sampai 70 tahun;

c. Lanjut usia tua (old) antara 75 sampai 90 tahun

d. Usia sangat tua (very old) diatas 90 tahun

Namun, berbeda dengan Departemen Kesehatan RI dalam mengelompokan Lansia menjadi:

a. Virilitas (Prasenium) yaitu masa persiapan usia lanjut yang menampakkan kematangan (usia 55-59) tahun;

b. Usia Lanjut Dini (senescen) yaitu kelompok yang mulai memasuki masa lanjut dini (usia 6064) tahun;

c. Lansia beresiko tinggi untuk menderita berbagai penyakit degeneratif 65 (enam puluh lima) tahun keatas.

Berdasakan Undang-Undang Nomor 13 Tahun 1998 dikatakan bahwa lansia adalah seseorang yang telah mencapai umur 60 tahun keatas (Notoatmodjo, 2007:275). Lansia adalah seseorang baik wanita maupun pria yang telah berusia 60 tahun ke atas dimana lansia secara fisik dapat dibedakan atas dua yaitu Lanjut Usia Potensial maupun Lanjut Usia tidak Potensial.

Lanjut Usia merupakan warga Negara yang memiliki hak sama dengan warga Negara lainnya. Dalam Undang-Undang Nomor 13 Tahun 1998 tentang kesejahteraan Lanjut Usia disebutkan bahwa Lanjut Usia mempunyai hak yang sama dalam kehidupan bermasyarakat, berbangsa dan bernegara (Notoatmodjo, 2007). Disamping itu juga disebutkan bahwa Lanjut Usia diberikan hak untuk mendapatkan pelayanan sosial yang meliputi:

a. Pelayanan keagamaan, mental dan spritual;

b. Pelayanan Kesehatan;

c. Pelayananan kesempatan kerja;

d. Pelayanan Pendidikan dan Pelatihan;

e. Kemudahan dalam penggunaan fasiltas, sarana dan prasarana umum;

f. Kemudahan dalam layanan dan bantuan hukum;

g. Perlindungan sosial;

h. Bantuan sosial

Daerah menghendaki agar urusan yang selama ini ditangani oleh kepada pemerintah daerah yang oleh undang-undang ditetapkan sebagai daerah otonom. Karena prinsip pemberian otonomi kepada pemerintah daerah pada dasarnya untuk membantu pemerintah pusat dalam menjalankan pemerintahan agar dapat melaksanakan pembangunan di daerah disamping itu pula konsep otonomi daerah tidak bisa dilepaskan dari teori desentralisasi yang sering dijadikan landasan bagi pembentukan pemerintahan daerah (Suacana, 2013). Usia Lanjut yang masih bisa beraktifitas dan memiliki ketrampilan pantas diberi kesempatan untuk tetap bekerja dan membaur dimasyarakat (Komisi, 2009:28)

Pasal 7 Undang-Undang Nomor 13 Tahun 1998 tentang Kesejahteraan Lanjut Usia menegaskan bahwa Pemerintah bertugas mengarahkan, membimbing dan menciptakan suasana yang menunjang bagi terlaksananya upaya peningkatan kesejahteraan sosial lanjut usia.

Secara ekonomis penduduk usia lanjut dapat diklasifikasikan kepada tingkat ketergantungan atau kemandirian mereka. Penduduk usia lanjut dikelompokkan kedalam tiga kelompok yaitu:

1. Kelompok lanjut usia yang sudah uzur, pikun (smile) yaitu mereka yang sudah tidak mampu memenuhi kebutuhan dasar mereka; 
2. Kelompok Lanjut Usia yang produktif, yaitu lanjut usia yang mampu memenuhi kebutuhan mereka sendiri dan tidak tergantung pada pihak lain;

3. Kelompok Lanjut Usia yang miskin (destitute) yaitu lanjut usia yang secara relatif tidak dapat memenuhi kebutuhannya sendiri seperti pekerjaan atau pendapatan.

Kabupaten Badung salah satu Kabupaten yang ada di Bali sudah menerapkan untuk memberikan satunan bantuan jaminan sosial terhadap lansia yang ada di Kabuapten Badung dengan di keluarkannya Peraturan Bupati Badung Nomor 38 Tahun 2018 tetang Bantuan Perindungan Sosial Lanjut Usia. Santunan yang diberikan bagi warga lanjut usia (lansia) di Kabupaten Badung telah di launching pada HUT Kota Mangupura ke 9 yang jatuh pada tanggal 16 November 2018. Dengan dikeluarkannya Peraturan Bupati tersebut harapan hidup yang lebih baik dan lebih sejahtera bagi Lansia yang ada di Kabupaten Badung menjadi lebih terjamin dengan adanya pemberian santunan sosial. Didalam Pasal 3 ayat (1) Perbup No 38 Tahun 2018 tentang Bantuan Perlindungan Sosial Lanjut Usia disebutkan bahwa Penerima Bantuan Perlindungan Lanjut Usia Daerah diperuntukan bagi Lanjut USIA:

a. Tidak potensial paling rendah 72 (tujuh puluh dua) tahun;

b. 60 (enam puluh) tahun keatas dan tidak berdaya (bedridden);

c. Bukan Lanjut Usia yang sedang menerima pensiun/santunan pemerintah/ lembaga sosial;

d. Bukan Lanjut Usia yang menjadi binaan dan tanggungjawab Panti Sosial Tresna Werdha/ Panti Sosial.

Dalam ayat (2) Perbub Nomor 38 Tahun 2018 tentang Bantuan Perlindungan Sosial Lanjut Usia juga dijelaskan besaran uang santunan yang diterima oleh para Lanjut Usia sebesar Rp. 1.000 .000 ,- ( satu juta rupiah) bagi setiap Lansia yang berhak untuk mendapat santunan.

Bupati Badung telah menugaskan Dinas Sosial Kabupaten Badung sebagai instansi yang menaungi masalah-masalah sosial kemasyarakatan yang ada di Kabupaten Badung untuk melakukan verifikasi untuk terjun langsung keseluruh kecamatan yang ada di Kabupaten Badung untuk melakukan pendataan terhadap lansia-lansia yang pantas untuk menerima santunan sosial, Petugas dari Kantor Dinas Sosial Kabupaten Badung melakukan koordinasi dengan Kepala Desa/Lurah yang mewilayahi Desa untuk mendapatkan data jumlah lansia yang ada diwilayah desa di samping itu Kantor Dinas Sosial juga melakukan koordinasi dengan Dinas Kependudukan dan Catatan Sipil Kabupaten Badung untuk mevalidasi jumlah lanjut penduduk yang sudah dikatagorikan lanjut usia dan berhak atas santunan sosial sesuai dengan Pasal 3 Perbup Badung Nomor 38 Tahun 2018 tentang Bantuan Perlindungan Usia Lanjut, setelah diadakan pendataan yang mana hasilnya lansia yang berhak menerima gaji sebesar Rp. 1.000.000.,- (Satu Juta Rupiah) dengan terjun langsung kelapangan perbekel/lurah untuk memberikan dan memperoleh data yang pasti. Dan dari hasil verifikasi tersebut didapatkan data bahwa yang berhak mendapatkan bantuan sosial sebanyak 13104 (tiga belas ribu seratus empat) orang yang tersebar di 6 kecamatan yang ada di Kabupaten Badung dengan total dana yang dikeluarkan sebesar Rp. 52.416.000.000,- (lima puluh dua milyard empat ratus enam belas juta rupiah) sesuai dengan tabel dibawah ini:

Tabel 1: Rekapitulasi Bantuan Sosial Lanjut Usia di Kabupaten Badung Tahun 2018 Bulan: September s.d. Desember 2018

\begin{tabular}{|c|c|c|c|}
\hline No & Kecamatan & Jumlah Pemohon & Jumlah Dana \\
\hline 1 & Petang & 1229 Orang & Rp. 4.916.000.000,- \\
\hline 2 & Abiansemal & 3894 orang & Rp. 15.576.000.000,- \\
\hline 3 & Mengwi & 4672 orang & Rp. 18.688.000.000,- \\
\hline 4 & Kuta & 562 orang & Rp. 2.248.000.000,- \\
\hline 5 & Kuta Utara & 1467 orang & Rp. 5.868.000.000,- \\
\hline 6 & Kuta Selatan & 1280 orang & Rp. 5.120.000.000,- \\
\hline & Total & 13104 orang & Rp. 52.416.000.000,- \\
\hline
\end{tabular}

Sumber data dari Kantor Dinas Sosial Kabupaten Badung 
Setelah jumlah Lansia yang ada di Kabupaten Badung terdata maka SK Pencairan dana Bantuan Perlindungan Sosial ditandatangani oleh Bupati Badung sebagai Kepala Daerah yang mempunyai kewenangan dan seluruh Lansia yang mendapat Bantuan Sosial telah memiliki rekening di Bank Pembangunan Daerah Bali dikarenakan penyaluran bantuan tersebut disalurkan melalui Bank BPD Bali. Berdasarkan hasil wawancara yang dilakukan dengan Bapak Kepala Dinas Kabupaten Badung pada anggaran APBD Santunan Lansia akan diberikan untuk empat bulan, pencairan pertama akan diberikan selama tiga bulan yang dilaksanakan bertepatan dengan HUT Kota Mangupura pada tanggal 16 November 2018. Lansia yang akan menerima Bantuan Perlindungan Sosial di Kabupaten Badung harus memenuhi persyaratan administrasi yaitu:

a. Wajib menyetorkan fotocopy e-KTP atau surat keterangan dari Perbekel/ Lurah;

b. Foto Copy Kartu Keluarga Kabupaten Badung yang tercantum nama Lansia;

c. Serta fotocopy buku tabungan Bank BPD Bali atas nama Lansia yang akan menerima Bantuan Sosial.

d. Untuk Lansia Bedridden harus menyertakan surat kuasanya yang diketahui oleh Perbekel/ Lurah.

Perhatian Pemerintah Kabupaten Badung terhadap Usia Lanjut yang cukup besar perlu disusun dan dilaksanakan dalam serangkaian kebijakan dan perlakuan guna memberdayakan agar usia lanjut merasa lebih bahagia dan sejahtera. Upaya memberdayakan usia lanjut akan berhasil baik dirasakan manfaatnya oleh usia lanjut itu sendiri. Pemberdayaan mengandung arti membangkitkan kesadaran, membangkitan identitas diri, memunculkan kekuatan dan membuat seseorang menjadi lebih berdaya. Pemberdayaan penduduk usia lanjut melalui peningkatan kemampuan untuk tetap aktif dalam aktifitas produktif merupakan salah satu antisipasi agar mereka dapat mengurangi ketergantungan actual terhadap anggota keluarga yang lain.

Kesejahteraan sosial sebagai kegiatan yang terorganisasi dengan tujuan meningkatkan kesejahteraan dari segi social melalui pemberian bantuan kepada orang untuk memenuhi kebutuhankebutuhan didalam beberapa bidang seperti kehidupan keluarga dan anak, kesehatan, penyesuaian sosial, waktu senggang, standar-standar kehidupan dan hubungan- hubungan. Dari Survey yang secara acak Penulis lakukan terhadap beberapa lansia yang menerima bantuan sosial diantaranya Ni Wayan Budri, Umur 80 tahun dari Br. Desa, Desa Angantaka, Ni Made Nengah umur 71 tahun (karena bedridden) dari Br. Desa, Desa Angantaka, Jero Jempiring, umur 79 dari Br. Pande, Desa Abiansemal menyatakan bahwa dengan adanya Dana Bantuan Sosial yang di canangkan oleh Pemerintah Kabupaten sangat bermanfaat dikarenakan dapat memberikan kesejahteraan bagi para lansia.

Berdasarkan Peraturan Daerah Nomor 39 Tahun 2008 tentang Uraian Tugas Dinas Daerah dilingkungan Pemerintah Kabupaten Badung ditentukan bahwa Dinas Sosial mempunyai tugas pokok melaksanakan urusan pemerintah daerah dibidang Kesejahteraan Sosial berdasarkan otonomi dan tugas pembantuan.

Fungsi Dinas Sosial dalam melaksanakan tugas pokok sebagai mana dimaksud dalam Pasal 4 ayat (3) Peraturan Daerah Nomor 39 Tahun 2008 tentang Uraian Tugas Dinas Daerah dilingkungan Pemerintah Kabupaten Badung adalah :

a. Perumusan kebijakan teknis dibidang kesejahteraan sosial;

b. Penyelenggaraan urusan pemerintah dan pelayanan umum sesuai dengan lingkup tugasnya;

c. Pembinaan pelaksanaan tugas lain yang diberikan oleh Bupati sesuai dengan tugas dan fungsinya.

Dalam menjalankan tugas penegakan Peraturan Bupati Kabupaten Badung, Dinas Sosial Kabupaten Badung harus mampu menghadapi berbagai keadaan dan tantangan global. Namun yang lebih penting lagi tentunya Dinas Sosial Kabupaten Badung harus berupaya menempatkan fungsi pelayanan kesejahteraan sosial kepada masyarakat yang ada di Kabupaten Badung dibandingkan dengan penegakan hukum. Hal ini penting, sebagai usaha pencegahan agar masyarakat sadar hukum dan paham akan pentingnya kesejahteraan bagi para lansia yang kebutuhan hidup dan kelangsungan hidupnya sangat memerlukan bantuan baik berupa materi maupun moril yang tidak bisa dilakukan oleh para lansia yang ada di Kabupaten Badung. Dalam melaksanakan tugasnya Dinas Sosial sering kali Petugas dari dinas Sosial Kabupaten Badung menghadapi kendala dalam mendata keberadaan lanjut usia yang berhak mendapat santunan Sosial koordinasi antara instansi terkait sering menjadi penghambat dalam penyaluran santunan Sosial. 
Dari hasil Wawancara yang Penulis lakukan kepada Team Dinas Sosial yang di koordinir oleh IGAA Putu Seriasih, ST.M.Si selaku Kabid Perlindungan dan Jaminan Sosial pada Dinas Sosial Kabupaten Badung, I Gst. A. Dewi Widiasi.S.Sos Anggota Team Dinas Sosial dan I Gede Arya Widastra Anggota Team Dinas Sosial pada tanggal 2 Januari 2020 yang menjadi hambatan Petugas dalam penyaluran bantuan sosial adalah dalam pengumpulan data, sering kali data yang terkumpul di Perbekel/ Lurah terlambat disetorkan oleh Aparat Desa sehingga proses verifikasi data menjadi terlambat juga Dinas Sosial bekerja sama dengan Dinas Kependudukan dan catatan sipil untuk memvalidasi data yang diperoleh dari lingkungan desa dan kecamatan yang ada di Kabupaten Badung, dalam pendataan tersebut dimana jumlah lansia yang ada di Kabupaten Badung mencapai ribuan orang membutuhkan pegawai yang cukup banyak sedangkan di wilayah desa/ kelurahan jumlah pegawai tidak memadai sehingga data yang telah diverifikasi mengalami keterlambatan sampai di Kantor Dinas Sosial Kabupaten Badung.

Disamping itu juga banyak data-data Lansia yang berhak mendapat bantuan sosial yang terkumpul dari desa/kelurahan tidak memenuhi persyaratan/ kriteria sebagai penerima bantuan lanjut usia, banyak sekali Lansia yang berhak atas bantuan Sosial Kartu Tanda Penduduknya tidak memiliki e-KTP sehingga dalam data-data Lansia yang sudah terlanjur direkam tanpa e-KTP harus didata kembali dikarenakan tidak bisa terbaca di sistem pendataan di Dinas Sosial, jumlah Lansia yang berhak atas Bantuan Sosial tersebut mencapai ribuan dan cukup memerlukan waktu dalam pendataan kembali sehingga mempengaruhi dalam proses penyaluran bantuan.

Dikarenakan kurang sosialisasi dan ketidak mengertian lansia dalam pencairan bantuan dana yang ditransfer melalui Bank BPD Bali, dimana harus melampirkan fotocopy buku tabungan di Bank $\mathrm{BPD}$, lansia melampirkan fotocopy buku tabungan dengan memakai nomor yang sama pada beberapa lansia, ini mengakibatkan terjadinya pemasukan dana yang double pada salah satu rekening buku tabungan, apabila dana sudah terlanjur di transfer kerekening tersebut maka Petugas dari Kantor Dinas Sosial akan memberitahukan Desa/ Kelurahan bahwa ada beberapa lansia menggunakan satu nomor rekening sama dengan nomor rekening lansia lain dan tindak lanjut petugas yaitu agar masingmasing lansia harus membuka rekening tabungan tersendiri atas nama diri sendiri. Apabila lansia sudah membuka rekening baru dan atas nama lansia sendiri maka Petugas Verifikator dari Dinas Sosial Kabupaten Badung akan segera menindaklanjuti dengan mengirmkan surat ke Bank BPD Bali mengenai proses penyaluran Dana Bantuan Sosial sesuai dengan yang berhak menerima sehingga aliran dana tidak menjadi tumpeng tindih.

Terkadang juga Lansia menghilangkan atau merusakkan buku rekening tabungannya dan kemudian membuat rekening buku tabungan baru tanpa melapor dan memberitahukan ke Desa/ Kelurahan atau Petugas dari Dinas Sosial bahwa rekening buku tabungan penerima bantuan sosial diganti dengan nomor yang baru sehingga dana bantuan sosial yang ditransfer tetap pada buku rekening lama dan lansia melakukan protes bahwa dana bantuannya tidak diterima sebenarnya kesalahan ada dipihak penerima tidak melaporkan pembuatan rekening baru ini juga akan menyebabkan terhambatnya penyaluran dana dikarenakan ketidak tahuan dari lansia tersebut pada akhirnya Petugas dari Dinas Sosial akan mengurus proses pelimpahan dana di Bank BPD Bali dari nomor rekening tabungan yang hilang atau rusak kerekening tabungan baru. Disamping itu juga Team Dinas Sosial Kabupaten Badung sering mengalami keterlambatan laporan dari Desa/Kelurahan jika ada lansia yang meninggal/atau melakukan perubahan lainnya. Terkadang koordinasi antara aparat Desa/ Kelurahan dengan Dinas Sosial kurang terjalin dan tidak cepat tanggapnya.

\section{SIMPULAN DAN SARAN}

\section{Simpulan}

Pelaksanaan Bantuan lanjut Usia yang mendapat bantuan/jaminan Sosial di Kabupaten Badung sudah menerapkan untuk memberikan satuan bantuan jaminan sosial terhadap lansia Peraturan Bupati Badung Nomor 38 Tahun 2018 tetang Bantuan Perindungan Sosial Lanjut Usia. Santunan yang diberikan bagi warga lanjut usia (lansia) di Kabupaten Badung telah di launching pada HUT Kota Mangupura ke 9 yang jatuh pada tanggal 16 November 2018 . Besaran uang santuan yang diterima oleh para Lanjut Usia sebesar Rp. 1.000.000, - (satu juta rupiah) bagi setiap Lansia yang berhak untuk mendapat santunan. Bupati Badung telah menugaskan Dinas Sosial Kabupaten Badung sebagai instansi yang menaungi masalah-masalah sosial kemasyarakatan ada di Kabupaten Badung untuk melakukan verifikasi untuk terjun langsung keseluruh kecamatan yang ada di Kabupaten Badung 
untuk melakukan pendataan terhadap lansia- lansia pantas untuk menerima santunan social. Dan dari hasil verifikasi tersebut didapatkan data bahwa berhak mendapatkan bantuan sosial sebanyak 13.104 (tiga belas ribu seratus empat) orang yang tersebar di 6 kecamatan di Kabupaten Badung. Faktor penghambat dalam pemberian Bantuan Sosial Lanjut Usia di Kabupaten Badung dalam pengumpulan data sering kali data yang terkumpul di Perbekel/ Lurah terlambat disetorkan oleh Aparat Desa banyak data-data Lansia yang berhak mendapat bantuan sosial terkumpul dari desa/ kelurahan tidak memenuhi persyaratan/ kriteria sebagai penerima bantuan lanjut usia Lansia berhak atas bantuan Sosial yang Kartu Tanda Penduduknya tidak memiliki e-KTP kurang sosialisasi dan ketidakmengertian lansia dalam pencairan bantuan dana yang ditransfer melalui BPD Bali, Lansia menghilangkan atau merusakkan buku rekening tabungannya dan kemudian membuat rekening buku tabungan baru tanpa melapor dan memberitahukan ke Desa/ Kelurahan atau Petugas dari Dinas Sosial Team Dinas Sosial Kabupaten Badung Adanya perbedaan jumlah data penerima bantuan sosial dengan berkas persyaratan dikirim dari Desa/Kelurahan. Jumlah tenaga verifikator yang ada di Kantor Dinas Sosial Kabupaten Badung hanya berjumlah 3(tiga) orang. Kurangnya Tenaga Pendamping lapangan untuk memverifikasi pengecekan syarat penerima Bantuan Sosial

\section{Saran}

Dalam program Pelaksanaan Bantuan lanjut usia yang ada di Kabupaten Badung diharapkan terus berkelanjutan bantuan tersebut tidak hanya berbentuk uang tunai juga diharapkan bagi lansia yang masih produktif diharapkan mendapat penyuluhan- penyuluhan mengenai usaha-usaha produktif yang bisa dilakukan oleh para lansia. Untuk meminimalis hambatan yang ditemui dilapangan dalam rangka penyaluran bantuan sosial disarankan antara instansi terkait yakni Pemerintah Kabupaten Badung dalam hal ini ditugaskan Dinas Sosial sebagai penyalur bantuan sosial dalam pendataannya harus tetap berkoordinasi dengan Dinas Kependudukan dan Catatan Sipil serta Desa/ Kelurahan sebagai pengumpul data warga sehingga tidak terjadi permohonan yang berulang-ulang, perlu adanya sosialisasi dari Dinas Sosial bagaimana dan siapa berhak mendapatkan Bantuan Sosial yang merupakan Program Pemerintah Kabupaten Badung untuk Para Lansia yang ada diwilayah Badung bermanfaat dan tepat sasaran.

\section{DAFTAR PUSTAKA}

Azizah. (2011). Keperawatan Usia Lanjut. Yogyakarta: Graha Ilmu.

Cirella, G. T., Bąk, M., Kozlak, A., Pawłowska, B., \& Borkowski, P. (2019). Transport innovations for elderly people. Research in Transportation Business and Management, 30(April), 100381.

Knapik, W. (2020). Stimulators and inhibitors of the development of social care and support for the elderly in Poland. Journal of Rural Studies, 76(March), 12-24.

Komisi, N. L. U. (2009). Profil Penduduk Lanjut Usia.

Liu, Y., Qu, Z., Meng, Z., \& Wang, S. (2020). Relationship between loneliness and quality of life in elderly empty nesters from the Wolong Panda Nature Reserve in Sichuan province, China, from the perspective of Rural Population and Social Sustainability. Physica A: Statistical Mechanics and Its Applications, 551(xxxx), 124154.

Muhamad, A. (2004). Hukum dan Penelitian Hukum. Bandung: Pt. Citra Bakti.

Notoatmodjo, S. (2007). Kesehatan Masyarakat: Ilmu dan Seni. Jakarta: Roneka Cipta.

Pak, T. Y. (2020). Social protection for happiness? The impact of social pension reform on subjective well-being of the Korean elderly. Journal of Policy Modeling, 42(2), 349-366.

Suacana, I. W. G. (2013). Transformasi Demokrasi dan Otonomi. Surabaya: PT. Revka Petra Media.

Subakti, N. (2001). Kajian Filsafat Hukum, Euthanasia dalam Hukum Indonesia. Surakarta: Muhammadiyah University Pres.

Supromin, C., \& Choonhakhlai, S. (2019). The provision of public services in municipalities in Thailand to improve the quality of life of elderly people. Kasetsart Journal of Social Sciences, 40(3), 619-627. 